\title{
A Comparison of Relationship Behaviors
}

\author{
Brian Eberly, Robert Pasnak*, Keith Renshaw, Linda Chrosniak \\ George Mason University, Fairfax, USA \\ Email: "rpasnak@gmu.edu
}

Received July 24 ${ }^{\text {th }}$ 2013; revised August $23^{\text {rd }}, 2013$; accepted September $24^{\text {th }}, 2013$

\begin{abstract}
Copyright (c) 2013 Brian Eberly et al. This is an open access article distributed under the Creative Commons Attribution License, which permits unrestricted use, distribution, and reproduction in any medium, provided the original work is properly cited.
\end{abstract}

\begin{abstract}
Pro-relationship behaviors—commitment, accommodation, sacrifice, and forgiveness—differ across relationships with parents, friends, and romantic partners. In order to test the extent to which the type of relationship plays a role in how willing a person is to accommodate, forgive, or sacrifice, participants were administered a series of questionnaires. The associations of these pro-relationship behaviors with commitment were compared across relationships. Although the tendency to accommodate, sacrifice, and forgive in one relationship was significantly correlated with the tendency to behave similarly in other relationships, there were significant differences from one relationship to another. For example, participants were significantly less likely to sacrifice for a friend than for a parent or a romantic partner. Conversely, participants were found to be significantly less accommodating for a parent than they were for a friend or for a romantic partner. Also, participants were significantly more likely to forgive friends than they were to forgive a romantic partner. All relationship behaviors were significantly correlated with commitment across all three relationship types, but the strength of these correlations was not consistent. This inconsistency is probably due to the differences in expectations that people have for different relationships. The friendships of college students are usually temporary, as friends graduate and move on, whereas relationships with parents last until death. Although there were inconsistencies, there were many significant correlations that showed that behavior in one relationship did predict behavior in other relationships. Just as behavior towards one's parents was related to behavior towards one's friends, it was also predictive of behavior towards romantic partners. Whether this applies to adolescents from other cultures, and whether it applies to non-university students, remains to be determined.
\end{abstract}

Keywords: Friends; Parents; Romantic Partners; Relationships

\section{Introduction}

Over the past few decades, a great deal of the research regarding interpersonal relationships has been centered on the concept of interdependence (Kelly \& Thiabaut, 1978). Interdependence refers to the way that the actions and feelings of one person are influenced by, and in turn, influence the behaviors and feelings of another in an interpersonal relationship. Interdependence also refers to the degree to which two people depend upon one another. Dependence can in turn be defined as the need for something specific, in this case a relationship, at any given time (Rusbult \& Van Lange, 2003).

Commitment to a relationship and another person, in many ways, reflects dependence. In the context of Rusbult's investment model, commitment is defined as the motivated desire for a relationship to persist (Rusbult, 1980, 1983; Rusbult \& Buunk, 1993). To date, the bulk of the research on interpersonal commitment has focused on romantic relationships. Such research suggests that commitment is linked with a number of variables, such as the extent of their investment (e.g., time, money, joint friends, etc.) in the relationship (e.g., Rusbult, 1980), attachment style (e.g., Joel, MacDonald, \& Shimotomai, 2011), selfesteem (e.g., Rill, Baiocchi, Hopper, Denker, \& Olson, 2009),

\footnotetext{
${ }^{*}$ Corresponding author.
}

and relationship satisfaction (e.g., Weigel, Brown, \& O’Riordan, 2011). From a more behavioral perspective, researchers also have found that individuals are likely to engage in a variety of relationship maintenance behaviors when prompted by a desire for the relationship to persist (Weiselquist et al., 1999; Kumashiro, Finkel, \& Rusbult, 2005; Kubacka et al., 2011). Behaviors in romantic relationships that have been identified as being prompted by feelings of commitment include accommodation (Rusbult, Verette, Whitney, Slovik, \& Lipkus, 1991; Weiselquist et al., 1999), sacrifice (Van Lange et al., 1997), and forgiveness (Braithwate, Selby, \& Fincham, 2011; Weiselquist, 2009; Fincham, Hall, \& Beach, 2006; Finkel, Rusbult, Kumashiro, \& Hannon, 2002).

Accommodation has been defined as an individual's willingness to inhibit potentially harmful tendencies and instead engage in constructive behaviors when the individual's partner has behaved in a potentially damaging manner. For example, although it irritates Adam when Beth makes plans for the both of them without consulting him, he tries to discuss his irritation in a calm manner instead of refusing to go along with her plans (Rusbult et al., 1991). Rusbult et al. (1991) conducted six studies that expanded upon previous literature and identified four main ways that individuals accommodate to a partner's transgressions: (a) exit-not accommodating and actively terminating the relationship; (b) voice-actively attempting to improve 
the situation through talking about the problem; (c) loyaltypassively waiting for things to get better while maintaining an optimistic outlook; (d) neglect-passively allowing the relationship to dissolve. Results of the studies revealed that individuals in relationships with high interdependence, regardless of the type of relationship, were more likely to engage in constructive accommodation like voice and loyalty behaviors, and less likely to engage in exit and neglect behaviors. In a separate study, Menzies-Toman and Lyndon (2005) discovered that individuals who were dependent upon their partner and subsequently committed to the persistence of the given relationship were more likely to engage in benign appraisals of a partner's transgressions. Thus, accommodation should be predicted by the level of commitment that an individual feels for a given relationship.

Sacrifice refers to choosing to forego a particular activity to be able to spend time with one's partner. Throughout the course of any relationship, it is inevitable that there will come times where the interests and desires of two people do not completely match, thus necessitating sacrifice on the part of one or both partners to maintain the relationship. Van Lange et al. (1997) conducted six separate studies (three cross-sectional surveys, one simulation experiment and two longitudinal studies) to investigate the role of commitment in sacrificing behavior. Results of all six studies revealed positive associations between levels of commitment and willingness to sacrifice. Other studies have confirmed this association in romantic relationships (e.g., Etcheverry \& Le, 2005; Stanley, Whitton, Sadberry, Clements, \& Markman, 2006), but we were unable to identify any studies of these factors in non-romantic relationships.

Defining forgiveness is a more difficult task, due to the difference between scholarly definitions of forgiveness and the layperson's definition (Fincham et al., 2006; Kearns \& Fincham, 2004). For the sake of the present research, forgiveness will be defined as, "a change whereby one becomes less motivated to think, feel and behave negatively (e.g., retaliate, withdraw) in regard to the offended" (Fincham et al., 2006: p. 4). What this means is that, instead of measuring forgiveness by how much an individual is able to forget about the transgression, forgiveness is instead viewed as the conscious absence of retaliatory or withdrawal behaviors as well as the gradual relief of negative affect that a person has towards that transgressor. In addition to this distinction, it is important to highlight how this construct differs from accommodation. Accommodation (as defined above) is a person's response to immediate points of conflict (e.g., being critical or rude), whereas forgiveness involves reactions to situations in which the person's trust in the other is violated by an action or behavior that contradicts the spoken or unspoken rules of that relationship. For example, accommodation would be used to assess how likely Adam would be to discuss problems with Beth when she is rude to him. On the other hand, a forgiveness measure would be used to measure how likely it is that Adam will feel negatively towards Beth if she were to expose a secret of his. In short, accommodation involves immediate responses, whereas forgiveness applies to long term behaviors and affects. Using this definition of forgiveness, multiple studies have confirmed a positive association between level of commitment and willingness to forgive in both romantic relationships (e.g., Finkel et al., 2002) and non-romantic relationships (e.g., Karremans \& Smith, 2010).

Based on this research, there is a good deal of support for the associations of commitment with these primary relationship maintenance behaviors in romantic relationships, with more limited support for these associations in friendships (e.g., Martz et al., 1998). However, much less is known about how consistent these behaviors (and their associations with commitment) are across relationships in individuals' lives. The limited research available suggests that in fact, the behaviors are somewhat consistent within individuals. For instance, although they did not explicitly compare behaviors across relationships, Perunovic and Holmes (2008) found that certain personality types are more prone towards accommodation in general. In a more complex study, McCullough and Hoyt (2002) assessed undergraduate students' likelihood to engage in avoidance, benevolence, and revenge when faced with transgressions by their romantic partner, their close same sex friend, and their mother or father. The students' preferences for revenge were more consistent across all relationships than their preferences for benevolence and avoidance, providing mixed evidence regarding consistency of behaviors across relationships. Correlations between responses to parents and other relationships also were examined in a 3-year longitudinal study of Dutch adolescents and their parents and friends (Van Doorn, Branje, Vander Valk, De Geode, \& Meeus, 2011). The researchers found that, in early and middle adolescence, the adolescents' style of problem solving and engagement in conflict with parents had a strong effect on their conflict style with friends, but not vice versa. In contrast, when the same adolescents were assessed 3 years later in the later stages of adolescence, results suggested that problem solving styles used with friends began to have an impact upon the style used with parents.

This latter study is of particular interest not only because it highlights the consistency of behaviors across relationships, but it begins to suggest that some relationships may be more influential than others at different times of life. From an interdependence perspective, the ways in which an individual perceives his or her actions and the actions of another individual are partially influenced by their own experiences as well as their social comparisons (Rusbult \& Van Lange, 2008, 2003; Kelley \& Thibaut, 1978). A possible implication is that the behaviors experienced in earlier relationships (e.g., with parents) may influence the individual's behaviors in subsequent relationships with friends and romantic partners. A first step in examining this issue is to more explicitly examine the consistency of behaviors across relationships, as was recently done by Van Doorn and colleagues (2011). The current study attempted to extend this initial work by focusing on three primary aims.

First, we aimed to examine the consistency of commitment and the relationship maintenance behaviors of accommodation, sacrifice, and forgiveness across relationships with parents, friends, and romantic partners. Second, we aimed to examine the associations of commitment with these behaviors across these three relationships, to determine whether associations are present in all types of relationships. Finally, we examined whether the association between commitment and all three relationship maintenance behaviors remained consistent across the types of relationships.

With regard to the first aim, we hypothesized that mean levels of commitment, accommodation, sacrifice, and forgiveness would not differ for the three types of relationships, and that the level of these behaviors would be positive correlated across all sets of relationships. With regard to the second aim, we hypothesized that each relationship maintenance behavior would be positively associated with commitment for all relationship types. 
Finally, with regard to the third aim, we hypothesized that the associations of commitment with each type of relationship maintenance behavior would not differ across the three types of relationships.

\section{Method}

\section{Participants}

College students, 34 males and 234 females, who were at least18 years of age, and involved in a romantic relationship, were recruited. Romantic relationships were defined as any interpersonal dyad involving sexually oriented acts of intimacy, such as kissing, close touching, and other sexually motivated acts of intimacy, which had persisted for a minimum of one month. All procedures were approved by the IRB of the university, and participants were awarded one participation credit upon completion of the study. No participants who began the survey failed to complete it. Perhaps this was because it was one of the easiest ways to earn the participation credit required in their course.

The students averaged 22.57 years of age $(S D=7.19)$ and $23.1 \%$ were freshmen, $15.3 \%$ sophomores, $27.6 \%$ juniors, $30.2 \%$ seniors, and $3.7 \%$ graduate students or non-credit students. The primary language of the participants was English (88.3\%), followed by Spanish (2.6\%), Arabic (1.5\%), and other (7.6\%). They reported living with parents (36.9\%), in a campus dormitory $(34.7 \%)$, off campus with roommates $(11.9 \%)$, off campus without roommates $3.4 \%$ ), or in some other living condition (13.1\%).

The students were asked to describe the people upon whom who the relationship questionnaires were based. The average age of parents (68 fathers; 198 mothers) was $51.56(S D=8.51)$. The average age for friends (66 male, 198 female) was 23.19 $(S D=8.19)$. Participants reported friendships to have lasted 44.85 months $(S D=30.48)$, and spending an average of 13.11 hours per week $(S D=19.83)$ with this friend. The average age of romantic partners was $24.18(S D=8.16)$, and mean length of romantic relationships was 24.98 months $(S D=24.76)$.

\section{Materials}

Commitment Scale. This is a 15-item measure taken from the investment model scale (Rusbult et al., 1998) used to measure the future goals and orientations of an individual for a given relationship (e.g. I spend a lot of time thinking about the future of our relationship). Responses on this 9-point scale range from 0 (Do not agree at all) to 8 (Completely agree). A score is attained by adding all items together and calculating the average. For the parent and friend versions of this measure, item 11 was removed.

Accommodation Scale. This is a 16-item scale (Rusbult, Verette, Whitney, Slovik, \& Lipkus, 1991) that examines the way that a person responds to particular conflict situations (e.g. When my partner says something really mean I threaten to leave him or her). Responses on this 9-point scale range from 0 (would never do this) to 8 (constantly does this). This measure has four subscales: exit, voice, loyalty, and neglect. It is scored by summing all items, while reverse scoring all exit and neglect items.

Sacrifice Scale. This is a 4-item scale (Van Lange, et al., 1997) that examines the willingness of a person to sacrifice specific activities that are important to him or her for the sake of maintaining the relationship. Respondents are asked to list four activities in order of importance that they hold in the individual's life. They then answer the following question: "Imagine that it was not possible for you to engage in Activity \#1 and maintain your relationship (impossible for reasons that are not your partner's fault). To what extent would you consider giving up activity (fill in the blank)?” Participants rate their willingness to sacrifice the specific activity on a 9-point scale ranging from 0 (I definitely would not give up this activity) to 8 (I definitely would not give up this activity). Their score is their average for all items.

Forgiveness Scale. This measure is a 16-item scale (Finkel et al., 2002) that examines "The way that I behave when my partner breaks the rules.” This can include any violation of the expectations that the individual has for how a partner should behave in a romantic relationship. Answers are scored on a 9point scale, ranging from 0 (would never do this) to 8 (constantly does this). This measure has four subscales: exit, voice, loyalty, and neglect. A score is attained by averaging all items, after reverse scoring all exit and loyalty items.

Relationship Assessment Scale (RAS). This is a 7-item scale (Hendrick, 1988) used to assess subjective satisfaction with a given relationship (i.e., how well does your partner meet your needs?). Answers are rated on a 5-point Likert scale, ranging from 1 (not well), to 5 (very well). The respondent's average score is obtained after reverse scoring items 4 and 7 . Although this scale was originally created to assess romantic relationships, Renshaw, McKnight, Kaska, and Blais (2011) created a generic version that they found to be sufficiently reliable: Cronbach's $\alpha=.89$ for parents, .87 for friends, and .90 for romantic partners.

\section{Procedure}

Participants were directed to a link connecting them to Survey Monkey, an online survey provider, and asked to complete the questionnaires above. All participants were given the study description and consent information. The questionnaires were given three times, once for each relationship being studied. Each was given with slight modifications and rewording for each relationship. For example, the accommodation item (when my partner says something really mean, I threaten to leave him or her) became (when my parent/friend says something really mean, I threaten to leave him or her). Similarly, pronoun and noun changes were made for each questionnaire so that the questions were directed at a specific relationship. Before answering the questionnaires for each type of interpersonal relationship (parent-child, romantic, friendship) participants were instructed explicitly that the following questions pertain to that specific relationship, and all answers should be given with that relationship in mind. In particular, for the parent-child relationship questions, participants were asked to answer questions with a particular parent in mind and were explicitly instructed not to switch in their mind from one parent to the other half way through the questionnaire. Similarly, before answering questions about their friendship participants were explicitly instructed to answer the questions about a CLOSE friend, and not just a friendly acquaintance. Also, as with the parent-child questions, participants were reminded to answer the questions with the SAME friend in mind for all of the friendship questions. 


\section{Analytic Plan}

Planned comparison with Bonferroni corrected $p$-values were used to compare mean scores for commitment, accommodation, sacrifice, forgiveness, and relationship satisfaction across romantic relationships, friendships, and parent-child relationships as well as find the correlations of each measure across the different relationship types. Next, the relative strength of correlations of commitment with all three behaviors plus relationship satisfaction within any given relationship was examined. To compare whether or not the strength of those correlations was significantly different from one relationship to another, a procedure recommended by Hays (1988), provides a Z-score, which can then be evaluated for significance. A significant result indicates that the magnitudes of the two correlations being compared are significantly different.

\section{Results}

\section{Mean Differences in Pro-Relationship Behaviors}

As can be seen in Table 1, participants reported significantly higher commitment for a romantic partner and a parent than for a friend. The difference between commitment for romantic partners and commitment for parents was not significant. This indicates that only mean levels of commitment for a parent and a romantic partner are similar to one another.

Accommodation for a romantic partner was not significantly different than accommodation for a friend (see Table 1); both were significantly greater than accommodation for a parent. Thus, although participants were as likely to accommodate a romantic partner as they would a friend, they were much less likely to accommodate a parent.

Table 1 also indicates that sacrifice for a romantic partner was greater than sacrifice for a friend, but less than sacrifice for a parent.

Similar to the findings for accommodation and sacrifice, the mean levels for forgiveness, seen in Table 1, were not consistent from one relationship to another. Forgiveness for a friend was significantly greater than forgiveness for a romantic partner, but not significantly different from forgiveness for a parent. Forgiveness for a parent was not significantly greater than forgiveness for a romantic partner; i.e., it was intermediate.

Finally, the means for satisfaction showed that there were significant mean differences from one relationship to another. As can be seen in Table 1, the mean level of satisfaction for romantic partners was significantly lower than both satisfaction with friends and satisfaction with parents. The latter two did not differ. In short, participants were less likely to be satisfied with their romantic partner than with either their parent or their friend.

In sum, the null hypotheses were disproven for each measure, and the pattern of the pro-relationship behaviors was different for each of the three types of relationships.

\section{Behaviors across Relationships}

Commitment for a parent was significantly correlated with commitment for friends; $r(231)=.18, p=.005$, while commitment in romantic relationships was not significantly correlated with either commitment in friendships, $r(228)=.11, p=.09$ or with parents, $r(229)=.10, p=.13$. All three correlations were low, with low effect sizes.

Accommodation in all three relationships were significantly correlated with one another such that, accommodation for a romantic partner was significantly correlated with accommodation for a friend; $r(206)=.49, p=.001$, and with accommodation for a parent; $r(201)=.49, p=.001$. Accommodation for a friend was also significantly correlated with accommodation for a parent; $r(203)=.43, p=000$. In other words, accommodation in any given relationship type was related to accommodation in both of the other two relationships, and to very nearly the same degree. These are medium effect sizes.

Sacrifice was also found to be correlated from one relationship type to another, such that sacrifice for romantic partners was correlated with sacrifice for a friend; $r(253)=.37, p=.001$, and with sacrifice for a parent; $r(251)=.36, p=.001$, which were both correlated with one another; $r(256)=.39, p=.001$. This indicates that the level of sacrifice expressed in one relationship will be related with the level of sacrifice expressed in any of the other two relationship types, and to nearly the same degree. Again, effect sizes are medium.

The pattern was essentially the same for forgiveness. Forgiveness in each relationship type was correlated with forgiveness in the other two relationship types, such that forgiveness for romantic partners was significantly correlated with forgiveness for a friend; $r(206)=.32, p=.001$, and with forgiveness for a parent; $r(215)=.41, p=.001$, which were also correlated with one another; $r(220)=.46, p=.001$. This indicates that a person's level of forgiveness in any given relationship is related to the level of forgiveness that person exhibits in both of the other two relationship types. Effect sizes are medium.

Satisfaction for friends, was slightly correlated with satisfac-

Table 1.

Means, standard deviations, and mean comparisons for commitment, accommodation, sacrifice, forgiveness, and satisfaction in relationships with a parent, friend, and romantic partner.

\begin{tabular}{|c|c|c|c|c|c|c|}
\hline & \multicolumn{3}{|c|}{ Means (Standard Deviations) } & \multicolumn{3}{|c|}{ Mean Comparisons: t } \\
\hline & Romantic Partners & Friends & Parents & $\begin{array}{l}\text { Romantic Partners vs. } \\
\text { Friends }\end{array}$ & Friends vs. Parents & $\begin{array}{c}\text { Parents vs. Romantic } \\
\text { Partners }\end{array}$ \\
\hline Commitment & $7.143(1.69)$ & $6.61(1.56)$ & $6.97(1.48)$ & $3.83^{* * *}$ & $3.01^{* *}$ & 1.10 \\
\hline Accommodation & $5.217(1.14)$ & $5.25(1.03)$ & $4.63(2.04)$ & .17 & $4.98^{* * *}$ & $4.46^{* * *}$ \\
\hline Sacrifice & 4.164 (2.19) & 3.47 (1.96) & $4.90(.99)$ & $4.81^{* * *}$ & $8.32^{* * *}$ & $2.97^{* *}$ \\
\hline Forgiveness & $4.675(1.03)$ & $4.89(1.24)$ & $4.79(1.26)$ & $3.13^{* *}$ & .77 & 1.91 \\
\hline Satisfaction & $4.129(.87)$ & $4.27(.66)$ & $4.27(.83)$ & $2.34^{*}$ & .03 & $2.04^{*}$ \\
\hline
\end{tabular}

Note: ${ }^{*} p<.05 .{ }^{* *} p<.01 .{ }^{* * *} p<.001$. 
tion for both parents; $r(244)=.17, p=.009$, and romantic partners; $r(241)=.20, p=.002$. These are small effect sizes. Satisfaction for romantic partners, however, was not significantly correlated with satisfaction for parents; $r(238)=.09, p=.13$. In other words, satisfaction for a friend was shown to be related with satisfaction reported in the other two relationships, but satisfaction for a romantic partner was not related with satisfaction for a parent.

\section{Commitment and Behaviors}

The final analyses involved examining correlations of commitment with each relationship behavior as well as satisfaction. Then the strengths of correlations of commitment with each of the other variables across relationships were compared. All correlations for measures for relationships with a romantic partner are displayed in Table 2. The correlations for relationships with friend are shown in Table 3, and those for relationships with a parent in Table 4. Commitment and accommodation. Commitment was significantly correlated with accommodation in all three relationship types. Correlations from each type of relationship were compared using the procedure recommended by Hays (1988), which provides a z-score that indicates whether or not the difference in the magnitude of any two correlations is significant. Using this procedure revealed that the correlation of commitment with accommodation in romantic partners was not significantly different than the correlation found in friendships; $z=.25, p=.80$, or the correlation in relationships with a parent; $z=.79, p=.43$. The correlation of commitment with accommodation in friendships was also not significantly different than

Table 2.

Intercorrelations of measures of relationship with parents, friends, and romantic partners.

\begin{tabular}{|c|c|c|c|c|}
\hline Patents & 1 & 2 & 3 & 4 \\
\hline 1. Commitment & -- & & & \\
\hline 2. Sacrifice & $.29^{* * *}$ & -- & & \\
\hline 3. Accommodation & $.42^{* * *}$ & .07 & -- & \\
\hline 4. Forgiveness & $.48^{* * *}$ & .12 & $.66^{* * *}$ & -- \\
\hline 5. Satisfaction & $.74^{* * *}$ & .28 & $.41^{* * * *}$ & $.54^{* * *}$ \\
\hline Friends & 1 & 2 & 3 & 4 \\
\hline 1. Commitment & -- & & & \\
\hline 2. Sacrifice & $.28^{* * *}$ & -- & & \\
\hline 3. Accommodation & $.33^{* * *}$ & .07 & -- & \\
\hline 4. Forgiveness & $.18^{* *}$ & .03 & $.66^{* * *}$ & -- \\
\hline 5. Satisfaction & $.47^{* * *}$ & .09 & $.53^{* * *}$ & $.49^{* * *}$ \\
\hline Romantic Partners & 1 & 2 & 3 & 4 \\
\hline 1. Commitment & -- & & & \\
\hline 2. Sacrifice & $.45^{* * *}$ & -- & & \\
\hline 3. Accommodation & $.35^{* * *}$ & .06 & -- & \\
\hline 4. Forgiveness & $.29^{* * *}$ & $.14^{*}$ & $.78^{* * *}$ & -- \\
\hline 5. Satisfaction & $.65^{* * *}$ & $.24^{* * *}$ & $.51^{* * *}$ & $.44^{* * *}$ \\
\hline
\end{tabular}

Note: ${ }^{*} p<.05 .{ }^{* *} p<.01 .{ }^{* * *} p<.001$
Table 3.

Intercorrelations of measures of relationship with friends.

\begin{tabular}{ccccc}
\hline & 1 & 2 & 3 & 4 \\
\hline 1. Commitment & -- & & & \\
2. Sacrifice & $.28^{* * *}$ & -- & & \\
3. Accommodation & $.33^{* * *}$ & .07 & -- & \\
4. Forgiveness & $.18^{* * *}$ & .03 & $.66^{* * *}$ & -- \\
5. Satisfaction & $.47^{* * *}$ & .09 & $.53^{* * * *}$ & $.49^{* * * *}$ \\
\hline
\end{tabular}

Note: ${ }^{*} p<.05 .{ }^{* *} p<.01 .{ }^{* * *} p<.001$.

Table 4.

Intercorrelations of measures of relationship with romantic partners.

\begin{tabular}{ccccc}
\hline & 1 & 2 & 3 & 4 \\
\hline 1. Commitment & -- & & & \\
2. Sacrifice & $.45^{* * *}$ & -- & & \\
3. Accommodation & $.35^{* * *}$ & .06 & -- & \\
4. Forgiveness & $.29^{* * *}$ & $.14^{*}$ & $.78^{* * *}$ & -- \\
5. Satisfaction & $.65^{* * *}$ & $.24^{* * *}$ & $.51^{* * *}$ & $.44^{* * *}$ \\
\hline
\end{tabular}

Note: ${ }^{*} p<.05 .{ }^{* *} p<.01 .{ }^{* * *} p<.001$.

the correlation of commitment with accommodation for a parent; $\mathrm{z}=1.05, p=.30$. Hence, commitment was similarly associated with accommodation across all three relationship types.

Commitment and satisfaction. The correlations for commitment with sacrifice for romantic partners (shown in Table 2), friends (Table 3) and parents (Table 4) show that commitment was significantly correlated with sacrifice for all three relationship types. Analysis of these correlations indicates that the strength of the association of commitment with sacrifice for romantic partners was significantly greater than the association of commitment with sacrifice for friends; $z=1.98, p=.05$, and parents; $z=2.11, p=.03$, while the correlation of commitment with sacrifice for friendships was not significantly different from that in relationships with a parent; $z=1.05, p=.92$. Thus, sacrifice was more strongly tied with commitment in romantic relationships than in either friendships, or relationships with a parent.

Commitment and forgiveness. Similar to what the findings from Finkel et al. (2002), Commitment was found to be significantly associated with forgiveness in all three relationship types. All correlations can be found in Table 2 (for romantic partners), Table 3 (for friends), and Table 4 (for parents). The strength of the correlation of commitment with forgiveness for a parent was significantly greater than the correlation of commitment with forgiveness for a friend; $z=3.58, p=.001$, and also significantly greater than the correlation in romantic relationships; $z=$ 2.24, $p=.025$. The strength of the correlation of commitment with forgiveness was also not significantly different across romantic relationships and friendships; $z=1.31, p=.19$ ). In short, forgiveness is most strongly tied to commitment in relationships with a parent, the strength of the correlation with romantic partners is intermediate between relationships with a parent, and relationships with a friend.

Commitment and satisfaction. Lastly, the correlations be- 
tween commitment and relationship satisfaction across relationships with a parent, a friend, and a romantic partner, were analyzed and compared. Values for the correlation of commitment with satisfaction can be seen in Table 2 (for romantic partners), Table 3 (for friends), and Table 4 (for friends). The correlation of commitment with satisfaction for a parent was not significantly different from the correlation within romantic relationships; $\mathrm{z}=1.77, p=.08$, but the correlations in both of these relationships were significantly greater than the association within friendships; $z=4.76, p=.000 ; z=2.96, p=.003$, respectively. This shows that the satisfaction is more strongly tied to commitment in relationships with a romantic partner and a parent, than in friendships.

\section{Discussion}

This comprehensive study was designed to examine within the same sample and with the same measures whether relationship behaviors are relatively consistent from one relationship to another. To accomplish this, mean levels of commitment, accommodation, sacrifice, forgiveness, and satisfaction were compared for relationships for a parent, a friend, and a romantic partner. Additionally, this study attempted to build upon previous research with romantic partners (Weiselquist et al., 1999) to determine whether commitment is a significant predictor of accommodation, sacrifice, and forgiveness in other relationships.

There were differences in accommodation, forgiveness, and satisfaction across relationship types. Sacrifice for parents was greater than for either friends or romantic partners. Also, although commitment was correlated with all pro-relationship behaviors and with satisfaction, the strength of those associations differed from one type of one relationship to another. This indicates that there are some fundamental differences in the ways that people behave in different types of relationships.

\section{Commitment in Relationships}

Consistent with previous studies, accommodation (Rusbult et al., 1991; Finkel \& Campbell, 2001), sacrifice (Van Lange et al., 1997; Weiselquist et al., 1999), and forgiveness (Finkel et al., 2002; Fincham, Hall, \& Beach, 2006) were correlated with commitment in romantic relationships. Satisfaction was also strongly correlated with commitment in romantic relationships, which is consistent with the investment model of commitment (Rusbult, 1980). That model states that satisfaction is one of three primary predictors of commitment.

Forgiveness and commitment. Although the association between forgiveness and commitment was statistically signifycant in romantic relationships, it was not very strong. This indicates that even when people are committed to their romantic relationship, they may still have a hard time forgiving the romantic partner for perceived transgressions. This could be due to the types of expectations that people have for their romantic partners. This is consistent with a recent study by Felmlee, Sweet, and Sinclaire (2012) who found that the type of relationship impacts the expectations a person has for that relationship, which in turn impact how that person perceives the other person.

Sacrifice and commitment. Of the three relationship maintenance behaviors associated with commitment in romantic relationships, sacrifice was most strongly tied to commitment. This indicates that in romantic relationships, the level of commitment that a person feels impacts his or her willingness to sacrifice more than it influences other behaviors. Sacrifice was more closely tied with commitment in romantic relationships than to the other two types of relationships. People who are committed to their romantic partner are more willing to sacrifice than people who are equally committed to parents or friends.

Friendship and commitment. For friendships, all three relationship behaviors were correlated with commitment. Accommodation was the relationship behavior most correlated with commitment, while the correlation of forgiveness with commitment, even though statistically significant, was very small This indicates that for friends, the level of commitment felt impacts the likelihood that a person will be accommodative more strongly than it impacts forgiveness, while the impact on sacrifice is intermediate. The associations of accommodation, sacrifice, and forgiveness with commitment in friendships are also weaker than the same associations in the other two relationship types. In short, this indicates that even though a person might be committed to a friendship, it is not as likely that he or she will be as accommodating, forgiving, or satisfied, as he or she might be in a relationship with a parent or romantic partner to whom he or she was equally committed.

The mean scores across the different relationship types show that the students were least committed to relationships with friends, and least willing to sacrifice for them, but were most willing to accommodate or forgive them. An explanation for why people are less committed to their friends than to their other relationships is likely to be the types of expectations that people have for different types of relationships. For instance, college students may have the expectation that friends come and go, and there isn't too much that can be done about holding onto friendships. An expectation or belief like this would explain the lower levels of commitment and sacrifice that participants reported for friends, which is consistent with previous research (Felmlee, Sweet, \& Sinclaire, 2012). In sum, this study indicates that there is something about the friendships of college students that leads them to behave differently than they would in another type of relationship to which they were equally committed. To address this issue, future studies examining friendships, relationship expectations, and relationship behaviors need to be conducted with different populations.

Parents and commitment. In relationships with a parent, all three relationship behaviors and satisfaction were correlated with commitment. Although the correlation of sacrifice and commitment was statistically significant, it was much smaller than the correlations of accommodation and forgiveness with commitment to a parent. This may be due to the nature of relationships with parents, which are more permanent than the other types of relationships, and also to the wording of the sacrifice measure which uses extreme language to ascertain whether or not a person would be willing to sacrifice (i.e., if giving up this important activity were the only way for the relationship to persist, would you be willing to give it up). Since it is not as likely for a relationship with a parent to end as a result of a person's failure to give up an activity as it is for a romantic relationship or friendship to end for that reason, the threat implied in the sacrifice scale is not as realistic for the parental relationship.

In contrast, the correlations of accommodation and forgiveness with commitment to parents were greater than the same associations in the other two relationship types. This indicates that even though sacrifice is not as strongly tied to commitment in relationships with a parent, commitment is more likely to 
impact a person's willingness to accommodate and forgive a parent than either a romantic partner or a friend.

The mean levels of behaviors across relationship types modify the picture given by the correlations of behaviors with commitment. In this context, it is important to remember that correlation coefficients are not affected by the absolute values of scores, and so correlations with commitment do not reflect the actual levels of accommodation, sacrifice, and accommodation expressed. When those levels are compared, the college students were least likely to accommodate their parents, but at the same time were most likely to sacrifice for them. It is possible that the relatively permanent nature of the parent-child relationship makes the thought of losing that relationship very poignant and produces a willingness to sacrifice if that is necessary to maintain it. At the same time, because the thought of losing one's parent due to behavioral issues is not a regular concern, people may be less accommodating to their parents as opposed to with friends or romantic partners, because, for most people, there is little chance of losing their parents until many years have passed.

Even though there were significant differences between the level of certain behaviors in relationships with a parent, friend, or romantic partner, it is clear from the many significant correlations found that how individuals behave in one relationship is related to how they act in another relationship. This indicates that the behaviors learned and developed early in life impact the likelihood that people will use similar behaviors in other relationships, later in life. Just as problem solving styles spill over from children's relationships with parents to their relationships with their friends (Van Doorn et al., 2011) these same behaveiors may in turn spillover into their romantic relationships.

Kelley and Thibaut (1978) argued that the satisfaction a person feels for a given situation is influenced by expectations or comparisons with similar situations. Hence, a person's expectations for a certain type of relationship may influence how he or she will react in a given situation. Will they be forgiving, will they be accommodating, or not? Felmlee, Sweet, and Sinclair (2012) found significant differences in the types of expectations that men and women had for friends of different sexes, which then impacted how they evaluated friends within a specific situation. Thus, differences in expectations impact how a person evaluates the other person in a relationship. This is likely to be true for parent-child and romantic relationships as well as friendships, and the differences in evaluations would produce different behaviors.

\section{Conclusion}

In conclusion, this study highlighted that there are some distinct aspects of particular relationships that lead people to behave differently within them. At the same time, it also showed that relationship maintenance behaviors were usually correlated for relationships with romantic partners, friends, and parents, indicating that some type of spill over is occurring. Lastly, and most importantly, this study indicates that there is so much yet to be learned about how people engage in different pro-relationship behaviors.

\section{Limitations}

A major limitation of this research is that the population was college students, in a single university in one of the mid Atlantic stats of the USA. Different results might emerge with older or younger individuals, with non-students, or with students or non-students from different locales. We also note that except for the RAS, there is no psychometric information on the scales employed in this research. Different measures might also yield differences in results. Hence this paper yields useful information, but its applications are limited to the type of individuals surveyed and the measures employed.

\section{Future Research}

In order to gain a deeper understanding of how pro-relationship behaviors develop, in what contexts, and at what stage of development, future studies should compare effects across a variety of relationships at multiple stages of development. Additionally, it would be valuable to understand the beliefs and expectations that people have for a given type of relationship, and how expectations impact the behaviors in which people engage.

\section{REFERENCES}

Aron, A., \& Aron, E. N. (1986). Love as the expansion of self: Understanding attraction and satisfaction. New York: Hemisphere.

Aron, A., Aron, E. N., \& Smollen, D. (1992). Inclusion of Other in the Self Scale and the structure of interpersonal closeness. Journal of Personality and Social Psychology, 63, 596-612.

http://dx.doi.org/10.1037/0022-3514.63.4.596

Agnew, C. R., Rusbult, C. E., Van Lange, P. A. M., \& Langston, C. A. (1998). Cognitive interdependence: mental representation of close relationships. Journal of Personality and Social Psychology, 74, 13731395. http://dx.doi.org/10.1037/0022-3514.74.4.939

Bowlby, J. (1977). The making and breaking of affectional bonds. I. Aetiology and psychopathology in the light of attachment theory. An expanded version of the Fiftieth Maudsley Lecture, delivered before the Royal College of Psychiatrists, 19 November 1976. The British Journal of Psychiatry, 130, 201-210.

http://dx.doi.org/10.1192/bjp.130.3.201

Braithwaite, S. R., Selby, E. A., \& Fincham, F. D. (2011). Forgiveness and Relationship Satisfaction: Mediating Mechanisms. Journal of Family Psychology, 25, 551-559. http://dx.doi.org/10.1037/a0024526

Bui, K. V. T., Peplau, L. A., \& Hill, C. T. (1996). Testing the rusbult model of relationship commitment and stability in a 15-year study of heterosexual couples. Personality and Social Psychology Bulletin, 22, 1244-1257. http://dx.doi.org/10.1177/01461672962212005

Drigotas, S. M., Rusbult, C. E., \& Verette, J. (1999). Level of commitment, mutuality of commitment, and couple wellbeing. Personal Relationships, 6, 389-409.

http://dx.doi.org/10.1111/j.1475-6811.1999.tb00199.x

Felmlee, D., Sweet, E., \& Sinclair, H. (2012). Gender rules: Same- and cross-gender friendships norms. Sex Roles, 66, 518-529. http://dx.doi.org/10.1007/s11199-011-0109-z

Fincham, F. D., Hall, J., \& Beach, S. R. H. (2006). Forgiveness in marriage: Current status and future directions. Family Relations, 55, 415-427. http://dx.doi.org/10.1111/j.1741-3729.2005.callf.x-i1

Finkel, E. J., \& Campbell, W. K. (2001). Self-control and accommodation in close relationships: An interdependence analysis. Journal of Personality and Social Psychology, 81, 263. http://dx.doi.org/10.1037/0022-3514.81.2.263

Finkel, E. J., Rusbult, C. E., Kumashiro, M., \& Hannon, P. A. (2002). Dealing with betrayal in close relationships: Does commitment promote forgiveness? Journal of Personality and Social Psychology, 82, 956-974. http://dx.doi.org/10.1037/0022-3514.82.6.956

Hartup, W. W. (1992). Having friends, making friends, and keeping friends: Relationships as educational contexts. ERIC Digest. http://ericeece.org/pubs/digests/1992/Hartup92.html

Hartup, W. W., Laursen, B., Stewart, M. I., \& Eastenson, A. (1988). Con- 
flict and the friendship relations of young children. Child Development, 59, 1590-1600. http://dx.doi.org/10.2307/1130673

Hays, W. L. (1988). Statistics (4th ed.). Fort Worth, TX: Holt, Reinhart, \& Winston, Inc.

Hendricks, S. S. (1988). A generic measure of relationship satisfaction. Journal of Marriage and the Family, 50, 93-98. http://dx.doi.org/10.2307/352430

Hoyt, W. T., Fincham, F. D., McCullough, M. E., Maio, G., \& Davila, J. (2005). Responses to interpersonal transgressions in families: Forgivingness, forgivability, and relationship-specific effects. Journal of Personality and Social Psychology, 89, 375-394. http://dx.doi.org/10.1037/0022-3514.89.3.375

John, O. P., Naumann, L. P., \& Soto, C. J. (2008). Paradigm shift to the integrative big-five trait taxonomy: history, measurement, and conceptual issues. In O. P. John, R. W. Robins, \& L. A. Pervin (Eds.), Handbook of personality: Theory and research (pp. 114-158). New York, NY: Guilford Press.

Kearns, J. N., \& Fincham, F. D. (2004). A Prototype analysis of forgiveness. Personality and Social Psychology Bulletin, 30, 838-835. http://dx.doi.org/10.1177/0146167204264237

Kelley, H. H., \& Thibaut, J. (1978). Interpersonal relations: A theory of interdependence. New York: Wiley.

Kubacka, K. E., Finkenauer, C., Rusbult, C. E., \& Keijsers, L. (2011). Maintaining close relationships: Gratitude as a motivator and a detector of maintenance behavior. Personality and Social Psychology Bulletin, 37, 1362-1375. http://dx.doi.org/10.1177/0146167211412196

Kumashiro, M., Finkel, E. J., \& Rusbult, C. E. (2002). Self-respect and pro-relationship behavior in marital relationships. Journal of Personality, 70, 1009-1050. http://dx.doi.org/10.1111/1467-6494.05030

Martz, J. M., Verette, J., Arriaga, X. B., Slovik, L. F., Cox, C. L., \& Rusbult, C. E. (1998). Positive illusions in close relationships. Personal Relationships, 5, 150-181.

McCullough, M. E., Rachal, K. C., Sandage, S. J., Worthington Jr., E. L., Brown, S. W., \& Hight, T. L. (1998). Interpersonal forgiving in close relationships: II. Theoretical elaboration and measurement. Journal of Personality and Social Psychology, 75, 1586-1603. http://dx.doi.org/10.1037/0022-3514.75.6.1586

McCullough, M. E., \& Hoyt, W. T. (2002). Transgression-related motivational dispositions: Personality substrates of forgiveness and their links to the big five. Personality and Social Psychology Bulletin, 28, 1556-1573. http://dx.doi.org/10.1177/014616702237583

Menzies-Toman, D. A., \& Lydon, J. E. (2005). Commitment-motivated benign appraisals of partner transgressions: Do they facilitate accommodation? Journal of Social and Personal Relationships, 22, 111128. http://dx.doi.org/10.1177/0265407505049324

Murray, S. L., Holmes, J. G., \& Griffin, D. W. (1996). The benefits of positive illusions: Idealization and the construction of satisfaction in close relationships. Journal of Personality and Social Psychology, 70, 79-98. http://dx.doi.org/10.1037/0022-3514.70.1.79

Murray, S. L., Holmes, J. G., \& Griffin, D. W. (1996). The Self-fulfilling nature of positive illusions in romantic relationships: Love is not blind, but prescient. Journal of Personality and Social Psychology, 71, 1155-1180. http://dx.doi.org/10.1037/0022-3514.71.6.1155

Murray, S. L. (1999). The quest for conviction: Motivated cognition in romantic relationships. Psychological Inquiry, 10, 23-34. http://dx.doi.org/10.1207/s15327965pli1001_3

Murray, S. L., Holmes, J. G., \& Collins, N. L. (2006). Optimizing assurance: The risk regulation system in relationships. Psychological Bulletin, 132, 641-666.

http://dx.doi.org/10.1037/0033-2909.132.5.641
Renshaw, K. D., McKnight, P., Caska, C. M., \& Blais, R. K. (2011). The utility of the relationship assessment scale in multiple types of relationships. Journal of Social and Personal Relationships, 28, 435447. http://dx.doi.org/10.1177/0265407510377850

Rusbult, C. E. (1980). Commitment and satisfaction in romantic associations: A test of the investment model. Journal of Experimental Social Psychology, 16, 172-186. http://dx.doi.org/10.1016/0022-1031(80)90007-4

Rusbult, C. E. (1983). A longitudinal test of the investment model: The development (and deterioration) of satisfaction and commitment in heterosexual involvements. Journal of Personality and Social Psychology, 45, 101-117. http://dx.doi.org/10.1037/0022-3514.45.1.101

Rusbult, C. E., Verette, J., Whitney, G. A., Slovik, L. F., \& Lipkus, I. (1991). Accommodation processes in close relationships: Theory and preliminary empirical evidence. Journal of Personality and Social Psychology, 60, 53-78. http://dx.doi.org/10.1037/0022-3514.60.1.53

Rusbult, C. E., \& Buunk, B. P. (1993). Commitment processes in close relationships: An interdependence analysis. Journal of Social and Personal Relationships, 10, 175-204. http://dx.doi.org/10.1177/026540759301000202

Rusbult, C. E., \& Van Lange, P. A. M. (1996). Interdependence processes. In E. T. Higgins, \& A. Kruglanski (Eds.), Social psychology: Handbook of basic principles (pp. 564-596). New York: Guilford.

Rusbult, C. E., Martz, J. M., \& Agnew, C. R. (1998). The investment model scale: Measuring commitment level, satisfaction level, quality of alternatives, and investment size. Personal Relationships, 5, 357-391. http://dx.doi.org/10.1111/j.1475-6811.1998.tb00177.x

Rusbult, C. E., \& Van Lange, P. A. M. (2003). Interdependence, interaction, and relationships. Annual Review of Psychology, 54, 351-375. http://dx.doi.org/10.1146/annurev.psych.54.101601.145059

Rusbult, C. E., \& Van Lange, P. A. M. (2008). Why we need interdependence theory. Social and Personality Psychology Compass, 2, 2049-2070. http://dx.doi.org/10.1111/j.1751-9004.2008.00147.x

Taylor, D. A., Altman, I., \& Sorrentino, R. (1969). Interpersonal exchange as a function of rewards and costs and situational factors: Expectancy, confirmation-disconfirmation. Journal of Experimental Social Psychology, 5, 324-339. http://dx.doi.org/10.1016/0022-1031(69)90057-2

VanderDrift, L. E., Lewandowski, G. W., \& Agnew, C. R. (2010). Reduced self-expansion in current romance and interest in relationship alternatives. Journal of Social and Personal Relationships, 28 356-373. http://dx.doi.org/10.1177/0265407510382321

Van Lange, P. A. M., Drigotas, S. M., Rusbult, C. E., Arriaga, X. B., Witcher, B. S., \& Cox, C. L. (1997). Willingness to sacrifice in close relationships. Journal of Personality and Social Psychology, 72, 1373-1395. http://dx.doi.org/10.1037/0022-3514.72.6.1373

Van Doorn, M. D., Branje, S. J. T., VanderValk, I. E., De Goede, I. H. A., \& Meeus, W. H. J. (2011). Longitudinal spillover effects of conflict resolution styles between adolescent-parent relationships and adolescent friendships. Journal of Family Psychology, 25, 157-161. http://dx.doi.org/10.1037/a0022289

Wieselquist, J., Rusbult, C. E., Foster, C. A., \& Agnew, C. R. (1999). Interpersonal relationships and group processes: Commitment, prorelationship behavior, and trust in close relationships. Journal of Personality and Social Psychology, 77, 942-966. http://dx.doi.org/10.1037/0022-3514.77.5.942

Wieselquist, J. (2009). Interpersonal forgiveness, trust, and the investment model of commitment. Journal of Social and Personal Relationship, 26, 531-548. http://dx.doi.org/10.1177/0265407509347931 